Avaiable online at www.banglajol.info

Bangladesh J. Sci. Ind. Res. 43(3), 309-320, 2008
BANGLADESH JOURNAL OF SCIENTIFIC AND INDUSTRIAL RESEARCH

E-mail: bjsir07gmail.com

\title{
Combined Heat and Mass Transfer by Mixed Convection Unsteady MHD Flow with Constant Heat and Mass Fluxes
}

\author{
M. M. Alam, ${ }^{\mathrm{a}^{*}}$ M. M. Haque, ${ }^{\mathrm{a}}$ M. Delowar Hossain ${ }^{\mathrm{b}}$ and Z. Haque ${ }^{\mathrm{a}}$ \\ ${ }^{a}$ Mathematics Discipline, Khulna University, Khulna-9208 and \\ ${ }^{b}$ Department of Mathematics, Khulna University of Engineering \& Technology, \\ Khulna-9203, Bangladesh
}

\begin{abstract}
Combined heat and mass transfer by mixed convection unsteady MHD flow from a vertical porous plate with time dependent suction velocity and, constant heat and mass fluxes has been studied under the action of transverse applied magnetic field. The boundary layer equations have been transformed into dimensionless coupled nonlinear ordinary differential equations by similarity transformations. The solutions of the dimensionless coupled nonlinear ordinary differential equations are obtained by shooting iteration technique. The obtained numerical results are presented in the form of velocity, temperature and concentration distributions. Finally the effects of the pertinent parameters on the skin-friction coefficient are also examined.
\end{abstract}

Key words : Combined heat and mass transfer, MHD flow, and Constant heat and Mass fluxes

\section{Introduction}

The unsteady free convection flow past a vertical porous plate with variable suction in the presence of transverse magnetic field was discussed by Roy and Das (1978). They made a detailed evaluation of the effects of the suction parameter on the amplitude of the skin-friction and the rate of heat transfer. Later Pande et. al. (1979), Georgantopuolos (1979), Raptis et. al. (1981), Soundalgekar and Takher (1981) and many others elucidat- ed the various aspects of MHD free convection flows with suction at the plate.

Hossain and Ahmed (1990) investigated the MHD forced and free convection flow past a vertical plate with uniform heat flux. In light of the work of Tingwci et. al. (1982), Hossain and Ahmed (1990) demonstrated the effects of the magnetic parameter as well the Prandtl number (suitable for liquid

* Corresponding author 
metals) on the mixed convection only for the leading edge of the plate. However, Raptis and Perdikis (1982) made a numerical study of the combined free and forced convective flow through a very porous medium bounded by a semi-infinite vertical porous plate. In addition to other effects their results display the effect of the permeability parameter on the velocity.

However, in the above studies the thermal diffusion effect was ignored. Along with these studies, the effect of thermal diffusion on MHD free convection and mass transfer flows have also been considered by many investigators due to its important role, particularly, in isotopic separation and in mixtures between gases with very light molecular weight $\left(\mathrm{H}_{2}, \mathrm{H}_{6}\right)$ and medium molecular weight ( $\mathrm{N}_{2}$, air) (Eckert and Drake, 1972). Considering these aspects, model studies were carried out by many investigators of whom the names of Kafoussias(1992) and Alam et al. (2006) are worth mentioning. From the available literature, it appears that the effect of thermal and mass diffusions on combined heat and mass transfer by mixed convection unsteady MHD flow with constant heat and mass fluxes has not yet been considered.

In the present work, therefore, our aim is to investigate the combined heat and mass transfer by mixed convection on unsteady MHD flow from a vertical porous plate with thermal and mass diffusions, and constant heat and mass fluxes. The governing equa- tions of the problem contain the partial differential equations, which are transformed by similarity transformation into dimensionless ordinary coupled non-linear differential equations. The obtained equations are solved numerically by sixth order Runge Kutta method along with the Nachtsheim-Swigert iteration technique. The obtained solutions are shown graphically as well as in tabular form.

\section{The Governing equations}

Let us consider combined heat and mass transfer by mixed convection unsteady MHD flow of an electrically conducting viscous fluid past an infinite vertical porous plate $y=0$. The flow is assumed to be moving in the upward direction with a constant velocity $\mathrm{U}_{0}$. Taking the $x$-axis along the plate in upward direction and $y$-axis is normal to it. A uniform magnetic field $B$ is applied to the plate to be acting parallel to the $y$-axis, which is electrically non-conducting. The level of concentration of foreign mass is assumed high so that the thermal and mass diffusions are considered. The magnetic field is of the form $\mathbf{B}=\left(0, B_{0}, 0\right)$. The equation of the conservation of electric charge is, $\nabla . \mathbf{J}=0$, where $\mathbf{J}=\left(J_{x}, J_{y}, J_{z}\right)$, the direction of propagation is considered only along the $y$ axis and does not have any variation along the $y$-axis. The derivative of $J_{y}$ with respect to $\mathrm{y}$ is namely $\frac{\partial J_{\mathrm{y}}}{\partial y}=0$, which gives result $J_{y}=$ constant. Since the plate is electrically 
non-conducting, therefore this constant is zero and hence $J_{y}=0$ everywhere in the flow. It is assumed that the plate is infinite in extent and hence all the physical quantities depend on $\mathrm{y}$ and $t$. Thus accordance with the above assumptions and Boussinesq's approximation, the basic equations relevant to the problem are:

$\frac{\partial \mathrm{v}}{\partial \mathrm{y}}=0$

$\frac{\partial u}{\partial t}+v \frac{\partial u}{\partial y}=v \frac{\partial^{2} u}{\partial y^{2}}+g \beta\left(T-T_{\infty}\right)+$

$g \beta^{*}\left(C-C_{\infty}\right)+\frac{v}{K}\left(U_{0}-u\right)+\frac{\sigma^{\prime} \beta_{0}^{2}}{\rho}\left(U_{0}-u\right)$

$\frac{\partial T}{\partial t}+v \frac{\partial T}{\partial y}=\frac{k}{\rho c_{p}} \frac{\partial^{2} T}{\partial y^{2}}+\frac{v}{c_{p}}\left(\frac{\partial u}{\partial y}\right)^{2}+\frac{\sigma^{\prime} \beta_{0}^{2}}{\rho c_{p}}$

$\left(U_{0}-u\right)^{2}+\frac{D_{m} k_{T}}{c_{S} c_{p}} \frac{\partial^{2} C}{\partial y^{2}}$

$\frac{\partial C}{\partial t}+v \frac{\partial C}{\partial y}=D_{m} \frac{\partial^{2} C}{\partial y^{2}}+\frac{D_{m} k_{T}}{T_{m}} \frac{\partial^{2} T}{\partial y^{2}}$

and the boundary conditions for the problem are:

$$
\begin{aligned}
& u(0)=0, v(0)=v(t), \\
& \frac{\partial T(0)}{\partial y}=-\frac{Q}{k}, \frac{\partial C(0)}{\partial y}=-\frac{m}{D_{m}} \\
& u(\infty)=U_{0}, \\
& T(\infty) \rightarrow T_{\infty}, \quad C(\infty) \rightarrow C_{\infty}
\end{aligned}
$$

where $u$ and $v$ are the velocity components in $x$ - and $y$-direction respectively, $B_{0}$ is the applied constant magnetic field, $Q$ is the constant heat flux per unit area, $m$ is the constant mass flux per unit area,u is the kinematic viscosity, $g$ is the acceleration due to the gravity, ris the density, $\mathrm{b}$ is the coefficient of volume expansion, $\mathrm{b} *$ is the volumetric coefficient expansion with concentration. $T$ and $T_{\infty}$ are the temperature of the fluid inside the thermal boundary layer and the fluid temperature in the free stream respectively, while $C$ and $C_{\infty}$ are the corresponding concentration, $c_{p}$ is the specific heat at constant pressure, $T_{m}$ is the mean fluid temperature, $k_{T}$ is the thermal diffusion ratio, $D_{m}$ is the coefficient of mass diffusivity, $c_{s}$ is the concentration susceptibility and other symbols have their usual meaning.

Following the work of Sattar (1993), a transformation is now made as,

$u_{1}=U_{0}-u$

The equations (2) -(4) and the boundary conditions (5), respectively, transform to

$$
\begin{aligned}
& \frac{\partial u_{1}}{\partial t}+v \frac{\partial u_{1}}{\partial y}=v \frac{\partial^{2} u_{1}}{\partial y^{2}}-g \beta\left(T-T_{\infty}\right)-g \beta^{*} \\
& \left(C-C_{\infty}\right)-\frac{v}{K} u_{1}-\frac{\sigma^{\prime} \beta_{0}^{2}}{\rho} u_{1} \\
& \frac{\partial T}{\partial t}+v \frac{\partial T}{\partial y}=\frac{k}{\rho c_{p}} \frac{\partial^{2} T}{\partial y^{2}}+\frac{v}{c_{p}}\left(\frac{\partial u_{1}}{\partial y}\right)^{2}+ \\
& \frac{\sigma^{\prime} \beta_{0}^{2}}{\rho c_{p}} u_{1}^{2}+\frac{D_{m} k_{T}}{c_{s} c_{p}} \frac{\partial^{2} C}{\partial y^{2}}
\end{aligned}
$$


$\frac{\partial C}{\partial t}+v \frac{\partial C}{\partial y}=D_{m} \frac{\partial^{2} C}{\partial y^{2}}+\frac{D_{m} k_{T}}{T_{m}} \frac{\partial^{2} T}{\partial y^{2}}$

$u_{1}(0)=U_{0}, v(0)=v(t)$,

$\frac{\partial T(0)}{\partial y}=-\frac{Q}{k}, \quad \frac{\partial C(0)}{\partial y}=-\frac{m}{D_{m}}$

$u_{1}(\infty) \rightarrow 0$,

$T(\infty) \rightarrow T_{\infty}, \quad C(\infty) \rightarrow C_{\infty}$

\section{Mathematical formulations}

In order to solve the above system of equations (7)-(9) under the boundary conditions (10), we adopt the well-defined similarity technique to obtain the similarity solutions. For this purpose the following non-dimensional variables are now introduced:

$\eta=\frac{y}{\sigma(t)}$

$u_{1}=U_{0} f(\eta)$

$-\mathrm{v}_{0}^{\mathrm{u}}=1-\mathrm{f}(\mathrm{u})$

$$
\begin{aligned}
& \prime(t)=-v_{0} \frac{v}{\sigma(t)} \\
& T=T_{\infty}+\frac{Q}{k} \sigma(t) \theta(\eta) \\
& C=C_{\infty}+\frac{m}{D_{m}} \sigma(t) \varphi(\eta)
\end{aligned}
$$

Equations (7) - (9) then become,

$$
\begin{aligned}
& f^{\prime \prime}+\left[\frac{\sigma}{v} \frac{\partial \sigma}{\partial t} \eta+v_{o}\right] f^{\prime}-G_{r} \theta-G_{m} \varphi- \\
& \left(K^{*}+M\right) f=0
\end{aligned}
$$

$$
\begin{aligned}
& \theta^{\prime \prime}+\left[\frac{\sigma}{v} \frac{\partial \sigma}{\partial t} \eta+v_{o}\right] P_{r} \theta^{\prime}-2 P_{r} \theta+P_{r} E_{c} f^{\prime 2}- \\
& +P_{r} E_{c} M f^{2}+P_{r} D_{f} \varphi^{\prime \prime}=0 \\
& \varphi^{\prime \prime}+\left[\frac{\sigma}{v} \frac{\partial \sigma}{\partial t} \eta+v_{o}\right] S_{c} \varphi^{\prime}-2 S_{c} \varphi+S_{c} S_{0} \theta^{\prime \prime}=0
\end{aligned}
$$

where

$G_{r}=g \beta \frac{Q}{k} \frac{\sigma(t)^{3}}{v U_{0}} \quad$ (Grashof number), $G_{m}=g \beta^{*} \frac{m}{D_{m}} \frac{\sigma(t)^{3}}{v U_{0}} \quad \begin{array}{r}\text { (Modified } \\ \text { Grashof number), }\end{array}$ $K^{*}=\frac{\sigma(t)^{2}}{K} \quad$ (Permiabily parameter), $M=\frac{\sigma^{\prime} \beta_{0}^{2} \sigma(t)^{2}}{\rho v} \quad$ (Magnetic parameter), $P_{r}=\frac{\mu c_{p}}{k}=\frac{\rho v c_{p}}{k} \quad$ (Prandtl number), $E_{c}=\frac{U_{0}^{2}}{c_{p} \sigma(t)} \frac{k}{Q} \quad$ (Eckert number), $D_{f}=\frac{k}{Q} \frac{m k_{T}}{v c_{s} c_{p}} \quad$ ( Dufour number), $S_{C}=\frac{v}{D_{m}} \quad$ (Smidth number), and, $\quad S_{0}=\frac{D_{m}{ }^{2} k_{T}}{v m T_{m}} \frac{Q}{k} \quad$ (Soret number) The equations (12)-(14) are similar except the term $\frac{\sigma}{v} \frac{\partial \sigma}{\partial t}$, where time $t$ appears 
explicitly. Thus the similarity condition $\quad+P_{r} D_{f} \varphi^{\prime \prime}=0$

requires that $\frac{\sigma}{v} \frac{\partial \sigma}{\partial t}$ in equations (12)-(14)

must be a constant quantity. Hence following the work of Sattar and Alam (1994) one can try a class of solutions of the equations (12)(14) by assuming that

$$
\frac{\sigma}{v} \frac{\partial \sigma}{\partial t}=c \text { (a constant) }
$$

Now from equation (15) we have,

$$
\sigma=\sqrt{2 c v t}
$$

It thus appear from (15) that by making a realistic choice of $c$ to be equal to in equation (16), the length scale $s$ becomes equal

to $\sigma=2 \sqrt{v t}$ which exactly corresponds to

the usual scaling factor considered for viscous unsteady boundary layer flows (Schlichting, 1968). Since $\mathrm{s}$ is a scaling factor as well as a similarity parameter, any value of $c$ in (16) would not change the nature of solutions except that the scale would be different. Finally introducing $c$ in equation (15), we have

$$
\frac{\sigma}{v} \frac{\partial \sigma}{\partial t}=2
$$

Using equation (17), the equations (12)-(14) yield

$$
\begin{aligned}
& f^{\prime \prime}+2 \xi f^{\prime}-G_{r} \theta-G_{m} \varphi-\left(K^{*}+M\right) f=0 \\
& \theta^{\prime \prime}+2 P_{r} \xi \theta^{\prime}-2 P_{r} \theta+P_{r} E_{c} f^{\prime 2}+P_{r} E_{c} M f^{2}
\end{aligned}
$$

$\varphi^{\prime \prime}+2 S_{c} \xi \varphi^{\prime}-2 S_{c} \varphi+S_{c} S_{0} \theta^{\prime \prime}=0$

where, $\xi=\eta+\frac{v_{0}}{2}$

The corresponding boundary conditions are obtained from equation (10) as,

$$
\left.\begin{array}{lll}
f(0)=1, & \theta^{\prime}(0)=-1, & \varphi^{\prime}(0)=-1 \\
f(\infty)=0, & \theta(\infty)=0, & \varphi(\infty)=0
\end{array}\right\}
$$

In the entire above equations prime denote the differentiation with respect to $\eta$.

\section{Skin friction co-efficient}

The skin friction coefficient at the plate is the quantities of chief physical interest. The shearing stress at the plate is generally known as the skin friction, the equation defining the skin friction is

$$
\tau=\mu\left(\frac{\partial u}{\partial y}\right)_{y=0} \quad \text { i.e. } \tau \propto f^{\prime \prime}(0)
$$

The next section deals the solution technique of the problem.

\section{Numerical solution}

The set of ordinary coupled non-linear differential equations (18)-(20) with the boundary conditions (21) for this problem are very difficult to solve analytically; so numerical procedures are adopted to obtain their solution. Here we use the standard initial value solver, namely the sixth order Runge Kutta method along with Nachtsheim-Swigert iteration technique. 
In a Nachtsheim-Swigert iteration technique, the missing (unspecified) initial condition at the initial point of the interval is assumed and the differential equation is then integrated numerically as an initial value problem to the terminal point. The accuracy of the assumed missing initial condition is then checked by comparing the calculated value of the dependent variable at the terminal point with its given value there. If a difference exists, another value of the missing initial condition must be assumed and the process is repeated. This process in continued until the agreement between the calculated and the given condition at the terminal point is within the specified degree of accuracy. For this type of iterative approach, on naturally inquires whether or not there is a systematic way of finding each succeeding (assumed) value of the missing initial condition. The Nachtsheim-Swigert iteration technique thus needs to be discussed elaborately. The boundary conditions (21) associated with the non-linear coupled ordinary differential equations (18)-(20) of the boundary layer type is of two point asymptotic classes. Two point boundary conditions have values of the depended variable specified at two different values of independent variable. Specification of asymptotic boundary conditions implies that the first derivative (and higher derivatives of the boundary layer equations, if exist) of the dependent variable approaches to zero and the value of the velocity approaches to unity as the other specified value of the independent variable is approached. The method of numerical integration of two point asymptotic boundary value problem of the boundary layer type, the initial value method, requires that the problem be recast as an initial value problem. Thus it is necessary to set up as many boundary conditions as the surfaces there at infinity. The governing differential equations are then integrated with these assumed surface boundary conditions. If the required outer boundary conditions are satisfied, a solution has been achieved. However, this is not generally the case. Hence a method must be devised to logically estimate the new surface boundary conditions for the next trial integration. Asymptotic boundary value problems such as those governing boundary layer equations become more complicated by the fact that the outer boundary condition is specified at infinity. In the trial integration infinity is numerically approximated by some large value of the independent variable. There is no general method of estimating this value. Selecting too small a maximum value for the independent variable may not allow the solution to asymptotically converge to the required accuracy. Selecting a large value may result in slow convergence or even divergence of the trial integration. Selecting too large a value of the independent variable is expensive in terms of computer time. NachtsheimSwigert developed an iteration method, which overcomes these difficulties. Extensions of the Nachtsheim-Swigert iteration to the above system of differential equa- 
tions (18)-(20) with boundary conditions are straight forward. In equation (21), there are four asymptotic boundary conditions and hence there will be three unknown surface

\section{Results and Discussion}

The numerical values of the velocity, the temperature, the concentration and the skin friction at the plate are obtained respectively for different values of the suction parameter $\left(v_{o}\right)$, the magnetic parameter $(M)$, the Soret number $\left(S_{o}\right)$, the Dufor number $\left(D_{f}\right)$, the Eckert number $\left(E_{c}\right)$ and for the fixed values of Prandtl number $\left(P_{r}\right)$, Schmidt number $\left(S_{c}\right)$, Grashof number $\left(G_{r}\right)$, Permeability parameter $(K)$ and modified Grashof number $\left(G_{m}\right)$. The values of $M$ and $G_{r}$ are taken to be large for cooling plate, since these large values corresponds to a strong magnetic field and to a cooling problem that is generally encountered in nuclear engineering in connection with the cooling of reactors.

The most important fluids are atmospheric air and water and so the results are limited for Prandtl number $P_{r}=0.71$ (in particular, 0.71 represents air at $20^{\circ} \mathrm{C}$ ). The value 0.60 is also considered for $S_{c}$, which represents the specific condition of the flow (in particular 0.60 corresponds to water vapor that represents a diffusivity chemical species of most common interest in air). In the calculations , $v_{0}, M, S_{o}, D_{f}, E_{c}$, and $G_{m}$ are however chosen arbitrarily.

With the above-mentioned parameters, the effects of various parameters on the velocity field are shown in Figs.1-5. The effect of the suction parameter $v_{0}$, on the velocity field is shown in Fig.1. It is observed from this figure that an increase in $v_{0}$, leads to an decrease in velocity in air $\left(P_{r}=0.71\right)$. The usual stabilizing effect of the suction parameter on the boundary layer growth is also evident from this figure and it is due to heat and mass transfer by mixed convection. The effect of the magnetic parameter $M$ on the velocity field is shown in Fig.(2). It is observed from this figure that an increase in magnetic parameter $M$ leads to a decrease in the velocity. The level of concentration of foreign mass is assumed high so that the thermal diffusion and mass diffusion (Soret and Dufour number) are considered. In Figs. 3-5, the variations of the velocity field for different values of Soret number $S_{o}$, Dufour number $D_{f}$ and Eckert number $\mathrm{E}$ are shown respectively. From these figures it is observed that the velocity increases with the increase of Soret number $S_{o}$ and Eckert number $E_{c}$. The same increasing behavior is observed for Dufour number $D_{f}$.

The effects of various parameters on temperature field are shown in Figs.6-10. It is observed from these figures that the temperature decreases as the suction parameter $v_{o}$ and magnetic parameter $M$ increase. Also it is observed from these figures that the temperature increases with the increase of Soret number $S_{o}$, Eckert number $E_{c}$ and Dufour number $D_{f}$. 


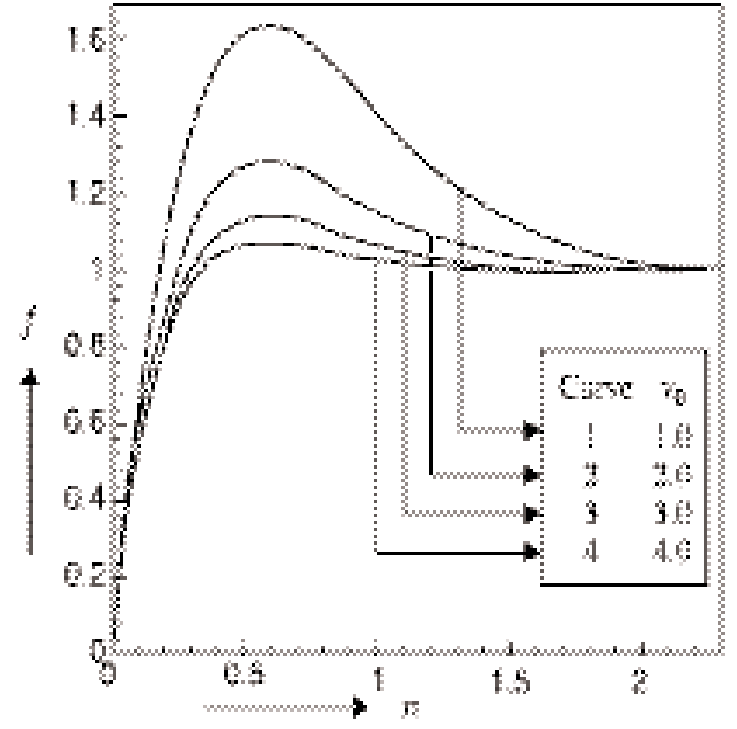

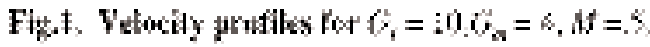

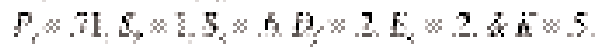

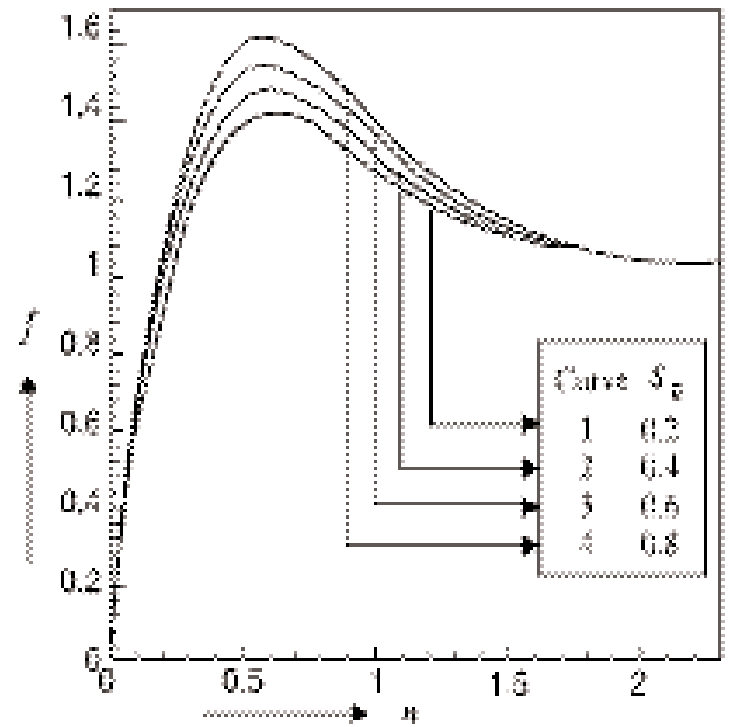

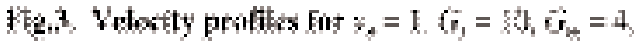

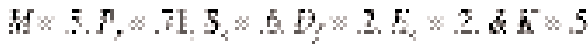

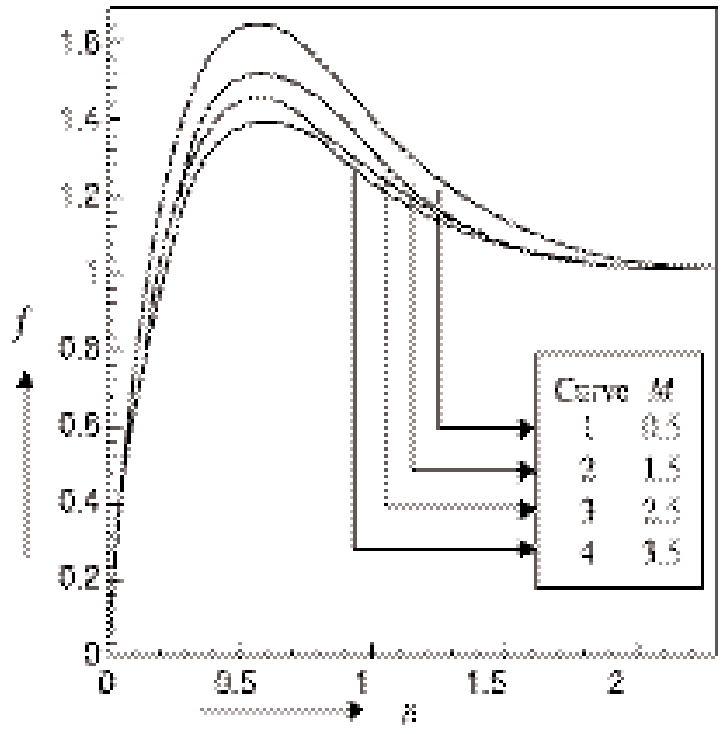

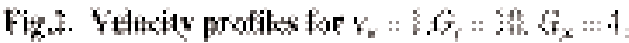

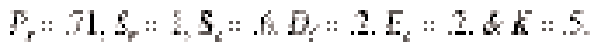

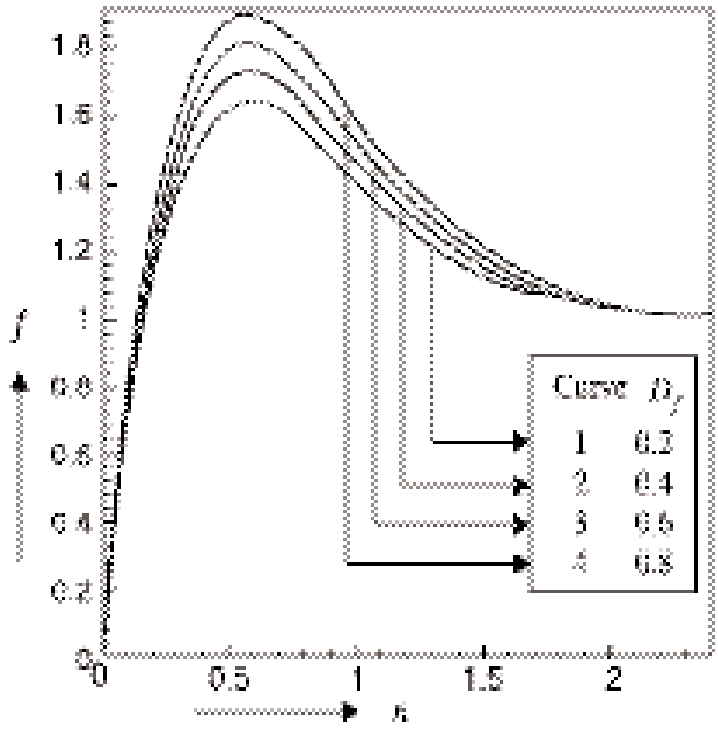

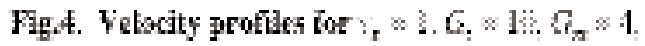

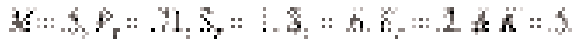




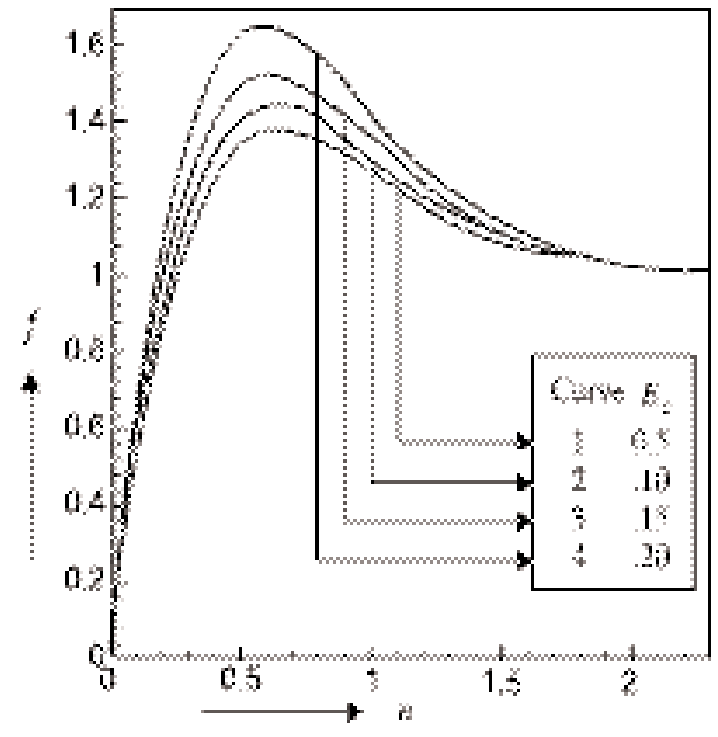

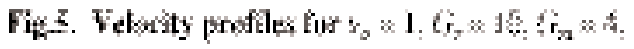

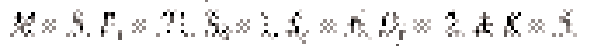

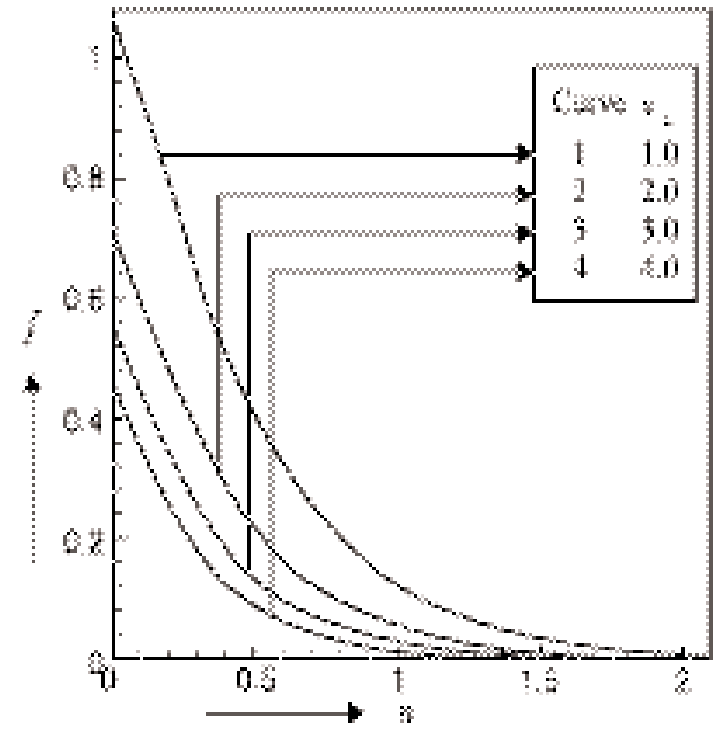

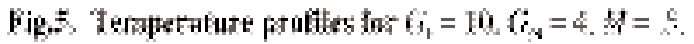

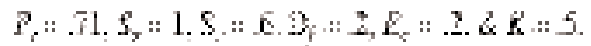

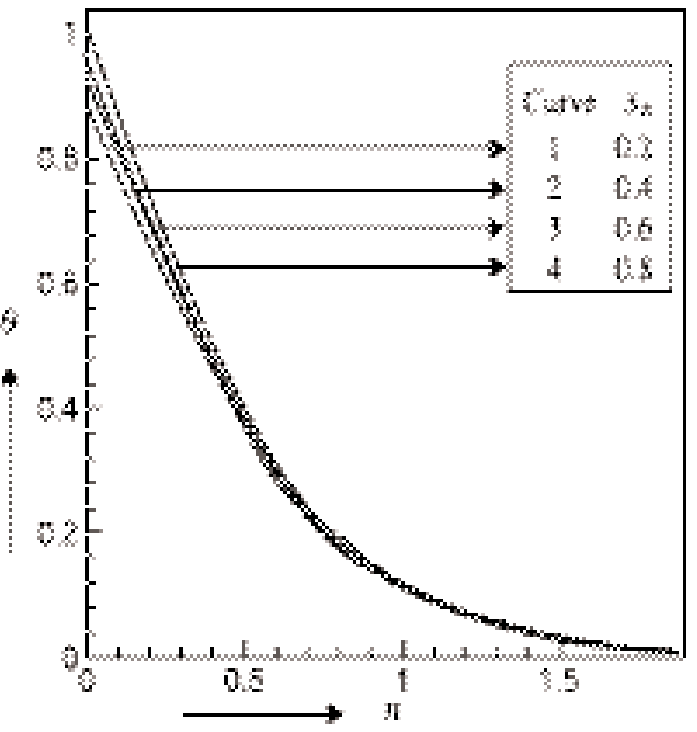

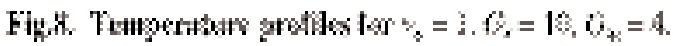

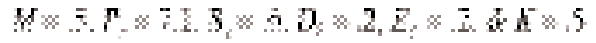

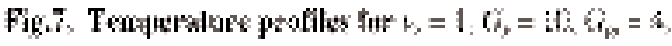

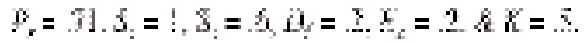

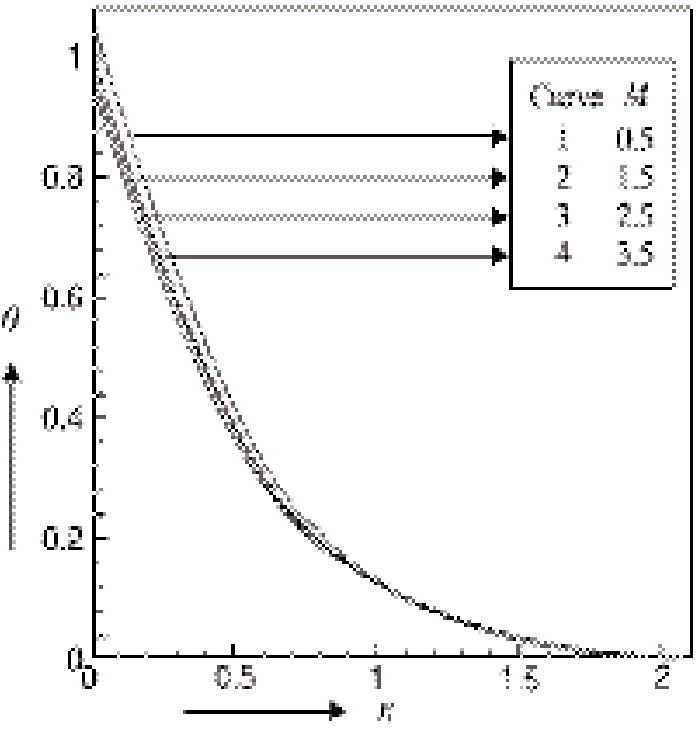




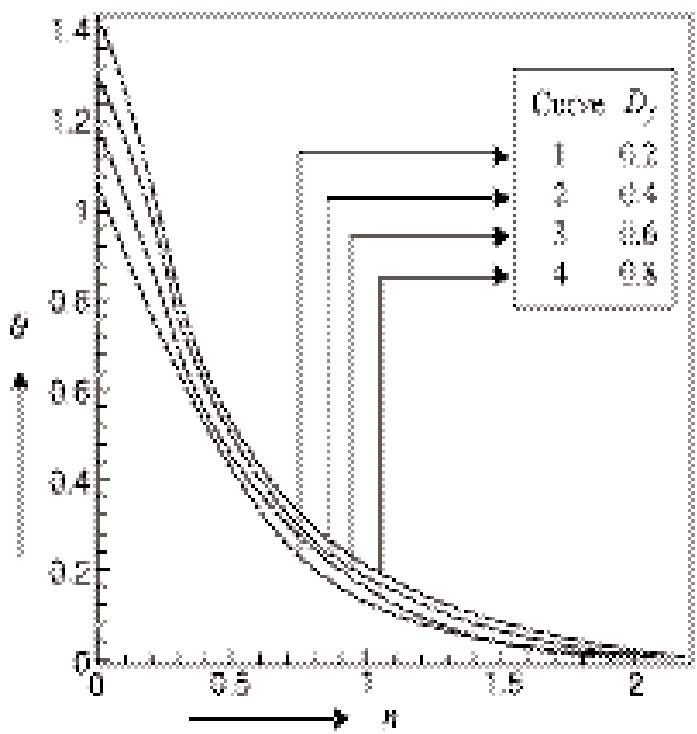

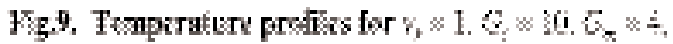

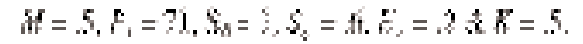

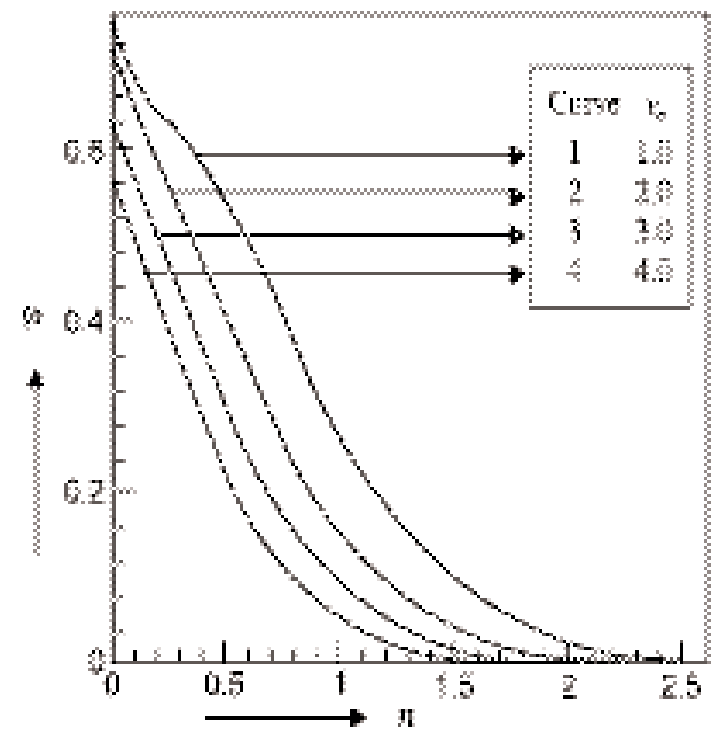

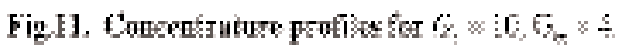

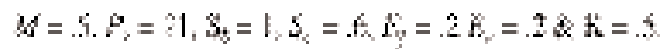

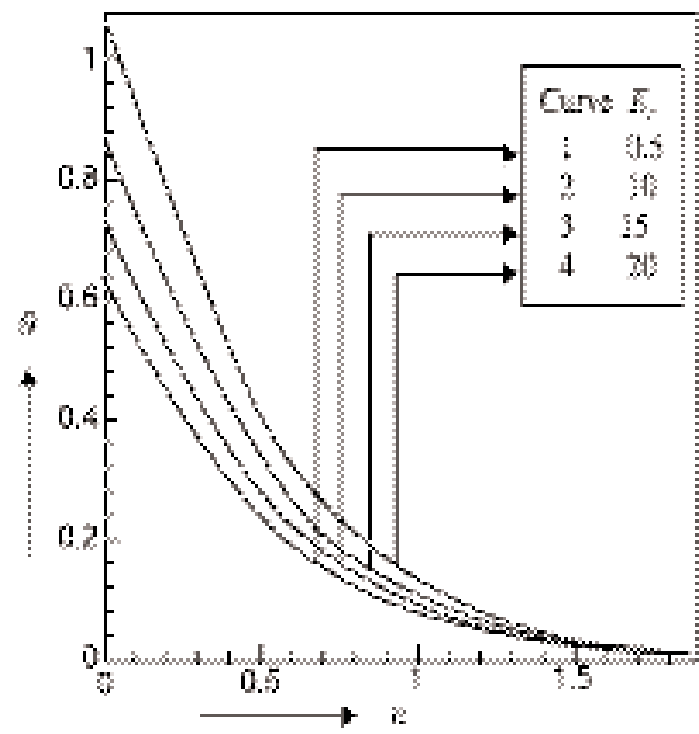

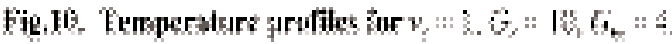

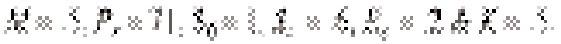

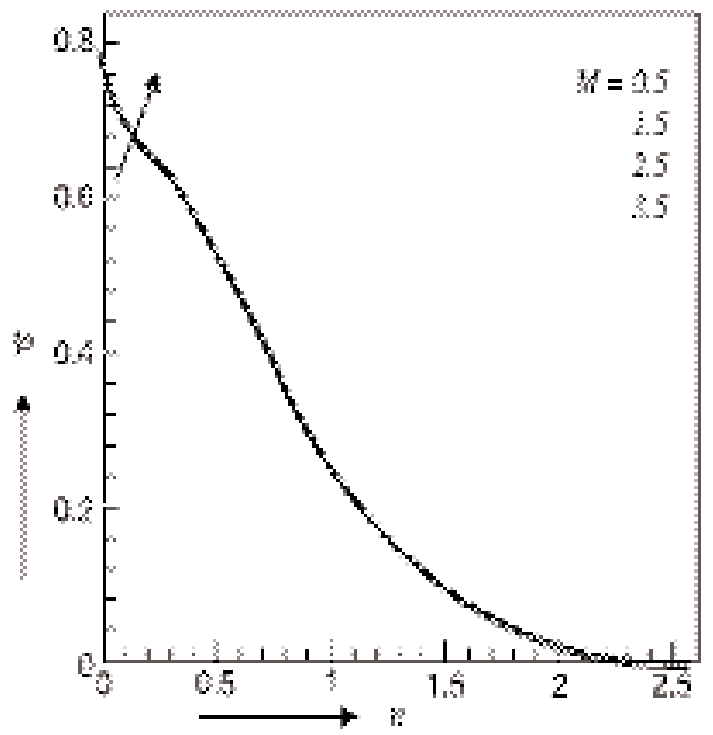

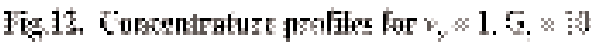

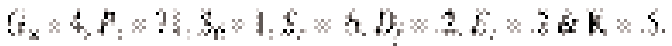




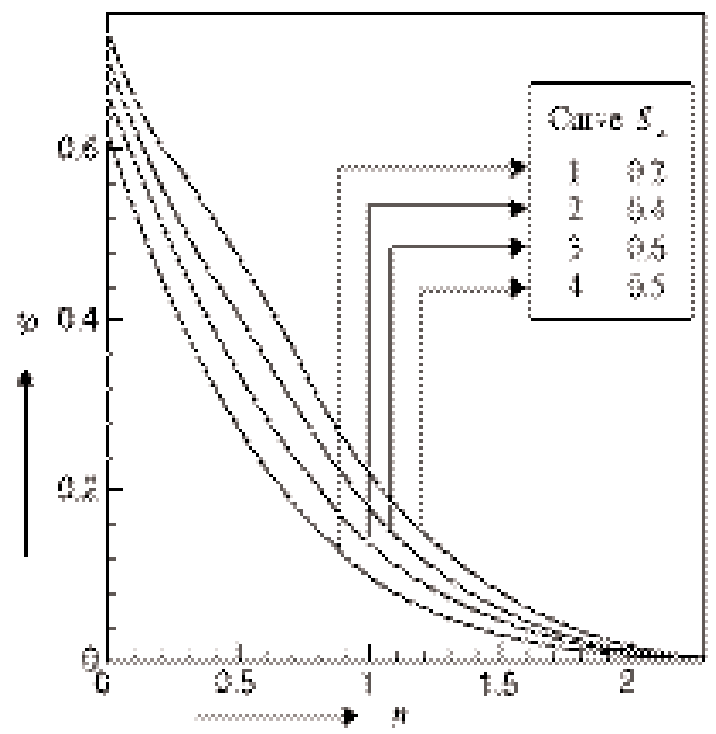

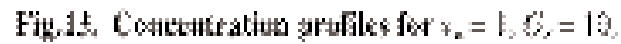

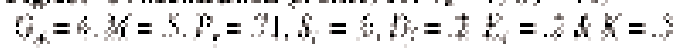

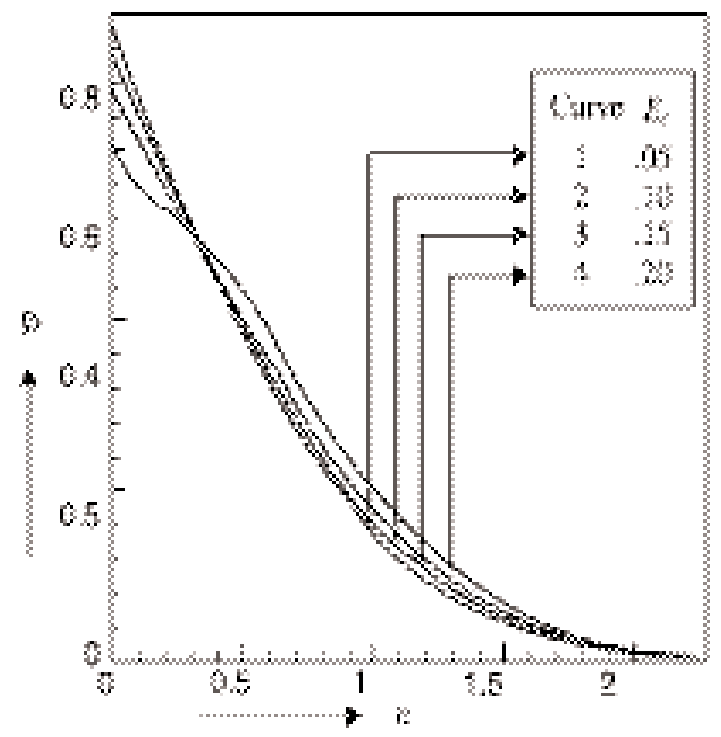

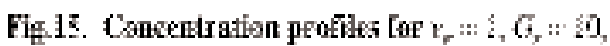

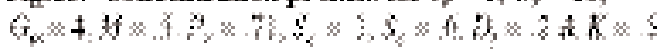

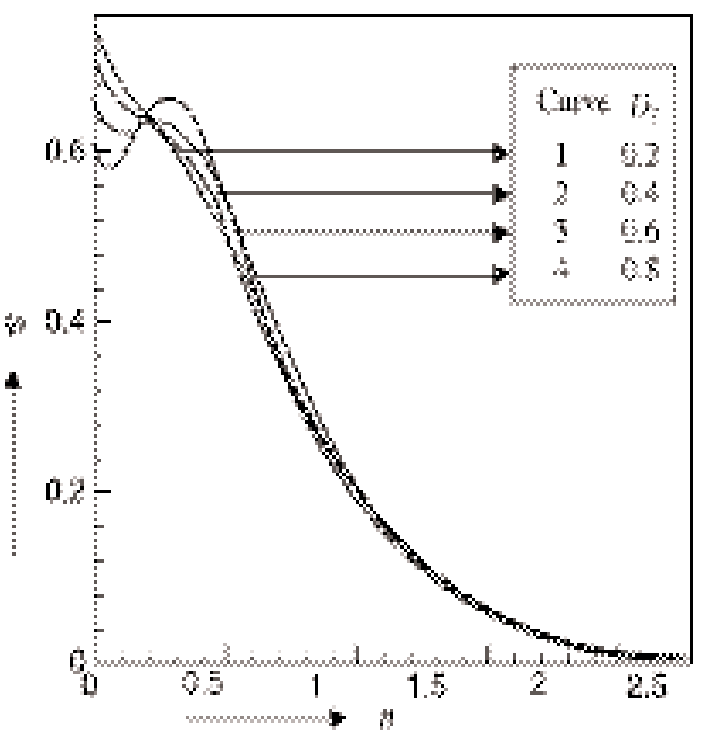

Fiz-14, Cencendrationt profikes for $v_{0}$ \&

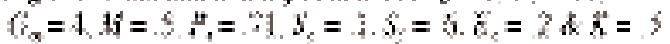


The effects of various parameters on the concentration field are shown in Figs.11-14. It is observed from Fig.11 that the concentration decreases with the increase of $v_{o}$ Figs.12 and 13 show that the concentration increases with the increase of magnetic parameter $M$ and Soret number $S_{o}$. But in case of magnetic parameter $M$, the decreasing effect is observed after the interval approx. $0<\eta<0$.5. In Figs. 14 and 15 , the concentration profiles for different values of Eckert number $E_{c}$ and Dufour number $D_{f}$ are shown respectively. It is observed from Figs.14 and 15 that the concentration decreases with the increase of Eckert number $E_{c}$ and Dufour number $D_{f}$ in a range approx. $0<\eta<0.5$, thereafter it has an increasing effect with the increase of $E_{c}$ and $D_{f}$.

\section{References}

Alam, M.M., Mondal, R.N., Uddin, M.S., Wahiduzzaman, M. Sattar, M.A. (2006), Dhaka University Journal of Science, 54(2): 127.

Eckert, E.R.G. Drake, R.M.. (1972) Analysis of Heat and Mass Transfer, McGraw-Hill Book Co. New York.

Georgantopoulos, G.A. (1979) Astrophysics Space Sci., 65(2): 433.
Hossian, M.A. Ahmed, M. (1990) Int. J. Heat Mass Transfer, 33: 571.

Kafoussias, N.G., (1992), Astrophysics Space Science, 192: 11.

Pande, G.G., Georgantopoulos, G.A. Douskos, C.N. (1979) Rev. Roum. Phys., 24(7): 691.

Raptis, A.A., Perdikis, C.P. Tzivanidis, G.J. (1981) Acta Phys. Acad. Sci. Hung., 50(4): 373.

Rapits, A.A. Perdikis, C.P. (1982) Astrophys. Space Sci. 84: 457.

Roy, A. Das, A.K. (1978) Ind. J. Pure Appl. Math., 9(11): 1214.

Soundalgekar, V.M. Takhar, H.S., (1981) J. Phys. Soc. Japan, 50(9): 3139.

Sattar, M.A. Alam, M.M. (1994) Indian Journal of Pure and Applied Mathematics, 25(6): 679-688.

Sattar, M.A. (1993) International Journal of Energy Research, 17: 1-7.

Schlichting, H. (1968) Boundary Layer Theory, McGraw-Hill, New York.

Tingwci, G., Bachrun, R. Dagnest, M. (1982) Int. J. Heat Mass Transfer, 25: 1061.

Received :November 05, 2007;

Accepted : February 03, 2008. 